G. Eisenreich

Lineare Algebra

und analytische Geometrie 
Mathematische Lehrbücher und Monographien

Herausgegeben von der Akademie der Wissenschaften der DDR Karl-Weierstraß-Institut für Mathematik

I. Abteilung

Mathematische Lehrbücher

Band 33

Lineare Algebra

und analytische Geometrie

von G. Eisenreich 


\section{Lineare Algebra und analytische Geometrie}

von Günther Eisenreich

Mit 107 Abbildungen und 2 Tabellen

2., beriçhtigte Auflage

Akademie-Verlag Berlin 1989 
Verfasser:

Prof. Dr. Günther Eisenreich

Karl-Marx-Universität Leipzig

Sektion Mathematik

ISBN 3-05-500263-6

ISSN 0076-5422

Erschienen im Akademie-Verlag Berlin, Leipziger Str. 3-4, Berlin, DDR - 1086

(C) Akademie-Verlag Berlin 1980

Lizenznummer: $202 \cdot 100 / 427 / 89$

Printed in the German Democratic Republic

Gesamtherstellung: VEB Druckerei „Gottfried Wilhelm Leibniz“,

Gräfenhainichen, DDR - 4450

Lektor: Dr. Reinhard Höppner

LSV 1024

Bestellnummer: 7624558 (6435)

04800 